\title{
Caracterização farmacoepidemiológica de pacientes em uso do antineoplásico oral capecitabina: perfil de adesão ao tratamento e análise de qualidade de vida
}

\author{
Rafael N. de Souza*, Natalia C. Duarte, Joao Carlos C. Teixeira, Mariana R. B. Medeiros, Thiago S. Cobaxo, \\ Carmen S. Passos, Patrícia Moriel.
}

\begin{abstract}
Resumo
A Capecitabina é um antineoplásico oral indicado para diversos tipos de neoplasias que apresenta vários efeitos adversos que podem comprometer a qualidade de vida dos pacientes e a adesão ao tratamento.O estudo foi conduzido no Hospital de Clínicas (HC) da Universidade Estadual de Campinas (UNICAMP) com 50 pacientes com diagnóstico de câncer colorretal ou gástrico em início de tratamento. Foram feitas caracterização farmacoepidemiológica, perfil de adesão e análise da qualidade de vida dos pacientes. A média de idade dos 50 pacientes foi de 59 anos, apresentam algum grau de etilismo, tabagismo, sobrepeso e o histórico familiar como fatores de risco ao desenvolvimento de tumores. Apenas os parâmetros 'Saúde/qualidade de vida global' e 'Função social' tiveram valores com diferenças, nesse caso aumento, estatisticamente relevantes. A adesão dos pacientes manteve-se em índices elevados em todos os ciclos avaliados.
\end{abstract}

\section{Palavras-chave:}

Capecetabina, câncer colorretal, câncer gástrico.

\section{Introdução}

A Capecitabina é um antineoplásico oral muito utilizado no tratamento de tumores sólidos como no câncer colorretal e no gástrico, porém possui diversos efeitos adversos que podem comprometer a qualidade de vida e adesão ao tratamento $O$ câncer colorretal é uma neoplasia que envolve o cólon, o reto e o canal anal, e possui um bom prognóstico quando detectado nos estágios iniciais, tendo sobrevida média global, em cinco anos, de $55 \%$ em países desenvolvidos e de $40 \%$ nos países em desenvolvimento. O câncer gástrico é a quinta causa mais comum de câncer no mundo, predominando em países em desenvolvimento, com médio e baixo IDH, e alta prevalência de infecção pela bactéria Helicobacter pylori (H. pylori)(1). No Brasil, estima-se que em 2018 haverá 12.920 casos novos de câncer de estômago em homens e 7.600 em mulheres, significando um risco estimado de 13,04 casos novos a cada 100 mil homens e 7,37 para cada 100 mil mulheres. Portanto, o objetivo deste estudo foi avaliar a qualidade de vida dos pacientes por meio da aplicação de questionários EORTC-QLC-30 (geral), EORTCQLQ-ST-022 (gástrico) e EORTC-QLQCR-29 (colorretal), a adesão ao tratamento por meio dos testes Morisky-Green e MedTake e caracterizar os pacientes em uso da Capecitabina. O estudo foi aprovado pelo Comite de ètica CAAE $\mathrm{n}^{\circ}$ 65683517.5.0000.5404.

\section{Resultados e Discussão}

O estudo foi desenvolvido no ambulatório de oncologia no Hospital de Clínicas da UNICAMP de janeiro de 2018 a setembro de 2018. Foram estudados 50 pacientes que tiveram indicação de capecitabina como tratamento para neoplasia gástrica e colorretal, destes $50 \%$ eram mulheres, com idade média de 59 anos, sendo $54 \%$ caucasianos, e $70 \%$ apresentaram KPS de 90 a 100. Do total, $46 \%$ dos pacientes estavam, no mínimo, em sobrepeso e possuíam algum grau de tabagismo e $58 \%$ do total consumiam álcool de forma moderara à mais que acentuada. A renda familiar per capita, para maioria dos pacientes, foi menor que 1 salário mínimo atual e $54 \%$ do total de pacientes possuíam o ensino fundamental incompleto. Dos 50 pacientes acompanhados no estudo,
39 responderam os questionários que avalia a adesão ao tratamento no retorno após consulta de caso novo (C1) e no retorno após o terceiro ciclo de quimioterapia (após C3).

De acordo com o teste Morisky-Green, em C1, 87\% dos pacientes apresentaram alta adesão, enquanto $10 \%$ apresentaram média adesão ao tratamento. Comparando com dados após o C3, vemos uma diminuição na taxa de alta adesão, que foi de $87 \%$ para $77 \%$ enquanto a taxa de média adesão aumentou de $10 \%$ para $20 \%$ após C3. Em relação ao MedTake, em C1, 42\% dos 39 pacientes demonstraram ter conhecimento de $100 \%$ de sua terapia. Esse valor chegou a $64 \%$ após o C3. O aumento no conhecimento da sua própria terapia pode levar o paciente a ter maiores índices de adesão ao tratamento. Em relação a qualidade de vida, os questionários foram aplicados antes do $\mathrm{C} 1$ e após $\mathrm{C} 3$. Apenas os parâmetros 'Saúde/qualidade de vida global' e 'Função social' tiveram valores com diferenças estatísticas, nesse caso aumento.

\section{Conclusões}

Com esse estudo foi possível determinar o perfil dos pacientes em uso de capecitabina. A adesão ao tratamento com capecitabina se mostrou alta e após o C3, em relação a qualidade de vida, os parâmetros 'Saúde/qualidade de vida global' e 'Função social' melhoraram. São necessários estudos com maior número de pacientes, para que se possa realizar análises com maior número de parâmetros estatisticamente relevantes a fim de se comparar com os dados já existentes na literatura.

\section{Agradecimentos}

Ao $\mathrm{PIBIC/CNPq}$, pelo financiamento. À equipe de oncologia do HC UNICAMP, à FCF UNICAMP e toda equipe do CLIPHAR.

1 Globocan: Global Cancer Facts \& Figures. American Cancer Society. 3rd edition.2012.. 